\title{
Experimental Models to Study the Role of Microbes in Host-Parasite Interactions
}

\author{
Megan A. Hahn and Nolwenn M. Dheilly* \\ School of Marine and Atmospheric Sciences, Stony Brook University, Stony Brook, NY, USA
}

Until recently, parasitic infections have been primarily studied as interactions between the parasite and the host, leaving out crucial players: microbes. The recent realization that microbes play key roles in the biology of all living organisms is not only challenging our understanding of host-parasite evolution, but it also provides new clues to develop new therapies and remediation strategies. In this paper we provide a review of promising and advanced experimental organismal systems to examine the dynamic of hostparasite-microbe interactions. We address the benefits of developing new experimental models appropriate to this new research area and identify systems that offer the best promises considering the nature of the interactions among hosts, parasites, and

OPEN ACCESS

Edited by: Robert Brucker, Rowland Institute at Harvard, USA

Reviewed by: Amparo Latorre, University of Valencia, Spain Adam Michael Reitzel, University of North Carolina at Charlotte, USA Reid Harris,

James Madison University, USA

*Correspondence:

Nolwenn M. Dheilly nolwenn.dheilly@stonybrook.edu

Specialty section: This article was submitted to Microbial Symbioses, a section of the journal Frontiers in Microbiology

Received: 27 May 2016 Accepted: 08 August 2016 Published: 23 August 2016

Citation: Hahn MA and Dheilly NM (2016)

Experimental Models to Study the Role of Microbes in Host-Parasite Interactions. Front. Microbiol. 7:1300. doi: 10.3389/fmicb.2016.01300 microbes. Based on these systems, we identify key criteria for selecting experimental models to elucidate the fundamental principles of these complex webs of interactions. It appears that no model is ideal and that complementary studies should be performed on different systems in order to understand the driving roles of microbes in host and parasite evolution.

Keywords: holobiont, symbioses, microbiome, microbe, mutualism, experimental models

\section{INTRODUCTION}

The term 'symbiosis' (from Greek "living together") was first coined by Albert Bernhardt Frank in 1877, when he described the relationship between fungi and algae in lichens, and was then used to define "the living together of unlike organisms" by de Bary (1879) and Theis et al. (2016). The modern definition of symbiosis encompasses all beneficial, neutral, and harmful long-term and intimate relationships, which correspond to a continuum of mutualistic, communal, and parasitic symbiosis (Bronstein, 2009; Cheng, 2012). Symbionts can contribute to phenotypic variations and thus to evolutionary innovation in their hosts (Margulis, 1991). Recent developments in molecular techniques have propelled a vast expansion of our knowledge regarding the presence, diversity, and abundance of non-cultivable microbes. It has revealed that most often, organisms are not associated with one single symbiont, but with a myriad of microbial symbionts that can independently or synergistically participate in their physiology and evolution (Rosenberg and Zilber-Rosenberg, 2011). The recognition of this inherent complexity of organisms led to the concept of the holobiont that integrates the host organism and all its associated microbes (Margulis, 1991). Two divergent opinions have recently risen. Some argue that the term holobiont and the concepts associated to it can lead to misunderstanding of evolutionary concepts in host-associated microbes (Moran and Sloan, 2015; Douglas and Werren, 2016). Others maintain that this new concept is necessary to embrace the pluralistic attributes of any plants and animals, whose phenotype result from 
multilevel selection on the host genome, the microbe genomes, and the hologenome (Bordenstein and Theis, 2015; Theis et al., 2016). This complexity and its implications has renewed interest in symbionts and is revolutionizing many fields of biology including parasitology and immunology. Of interest in this review, host-parasite interactions are now being re-considered in light of the microbiome (Dheilly, 2014). This has led to a better understanding of the pluralistic role of microbes in host defense and to new theories of parasite virulence strategies driven by their interaction with microbes (Dheilly et al., 2015b). Host and parasite microbiomes contribute to host and parasite fitness and impose new selection pressures on parasites and hosts, respectively (Figure 1). Alteration of any partner may cause a chain of responses in those remaining and change the outcome of infection.

\section{HOST DEFENSIVE SYMBIONTS}

Scientists have long recognized and accepted that mixed infection is the rule in natural environments and that microbes in the same host can directly and indirectly interfere with each other. Concomitant immunity was shown in Schistosomes (blood flukes) as early as 1969 and facilitation in 1971 (Kloetzel et al., 1971, 1977). We now know that resistance, competition, and facilitation can result from direct and indirect interactions among protozoa, helminthes, viruses, and bacteria (Cox, 2001). Thus, the net outcome of the host-parasite interaction can vary greatly in presence of other microbes, from harmful to neutral and beneficial. In particular, the concept of defensive mutualism led to the discovery of microbes acting in defense to parasites in many taxa, including fungi, mollusks, insects, plants, and vertebrates (Clay, 1988; White and Torres, 2009). Microbial symbionts are necessary for maturation of the immune system during early-life (Gollwitzer and Marsland, 2015) and later protect the host against pathogens via immune activation (Hall et al., 2008; Benson et al., 2009), production of antimicrobial factors, competition for resources or by limiting parasite adhesion to host cells (Cash, 2006; Kamada et al., 2012; Buffie and Pamer, 2013). Most importantly, microbe-mediated protection can evolve rapidly due to their large population size and short generation times, thus participating in host adaptation (King et al., 2016). In fact, symbionts may take over the evolutionary arms race against parasites, and alleviate the selection pressures on the host (Kwiatkowski et al., 2012), as demonstrated by the reduction in Drosophila melanogaster resistance to Drosophila $\mathrm{C}$ virus when associated with the defensive symbiont Wolbachia (Martinez et al., 2016a). The inter-regulation between microbiome and immune system has led to redefinition of this new unit that integrates host and microbe-encoded defenses into a single "holoimmunome" (Dheilly, 2014) or "microimmunosome" (Dietert, 2016).

A number of organismal systems were developed to study the role of defensive symbionts in the ecology and evolution of hosts and parasites. Many insects harbor microbial mutualists and studies of their role in defense to parasites have long been successful. Aphids have provided the most remarkable example of insect-associated defensive symbionts (see Oliver et al., 2014 for detailed review). In Acyrthosiphon pisum, the facultative symbionts Hamiltonella and Serratia provide defense against the parasitic wasp Aphidius ervi (Oliver et al., 2003, 2005) whereas Regiella provides resistance to the fungus Pandora neoaphidis (Scarborough et al., 2005). Because aphids have a parthenogenetic reproduction, clonal lines of aphids can be maintained indefinitely and the microbiome is manipulated by a combination of antibiotic treatments and micro-injection of symbionts. Aphids are thus ideal experimental models to understand the impact of defensive symbionts on the evolution of their hosts and parasites. For instance, it is employed to study the cost of defensive symbionts (Vorburger et al., 2013; Polin et al., 2014; Cayetano et al., 2015), their population dynamics (Oliver et al., 2008), their role in parasitoid community composition (Rothacher et al., 2016), the specificity of symbiontassociated defense (Martinez et al., 2016b), and to demonstrate that host symbiont's role in defense imposes new selection pressure on parasites (Oliver et al., 2012). Another biological system worth mentioning is the role of Wolbachia against viruses. Wolbachia is a reproductive parasite of the fruit fly Drosophila melanogaster (Fry et al., 2004) but it also imparts resistance to Drosophila C viruses, Cricket Paralysis Virus, Flock house virus, Nora virus, and West Nile Virus by reducing the viral load (Hedges et al., 2008; Teixeira et al., 2008; Osborne et al., 2009; Glaser and Meola, 2010). Knowledge gained from studying this organismal system has led to the discovery of a Wolbachia-induced resistance to many human parasites including Dengue virus, Chikungunya virus, Yellow fever virus, West Nile Virus, and malaria parasites in mosquitoes (Moreira et al., 2009; Bian et al., 2010; Van den Hurk et al., 2012). Clearly, integrating the role of defensive symbionts into our understanding of vector competence has implications for the control of disease transmission. For example, Wolbachiainfected mosquitoes have been released in natural environments as a preventative measure to limit the prevalence of Dengue virus (Hoffmann et al., 2011; Iturbe-Ormaetxe et al., 2011). The diversity of insects carrying defensive symbionts provides opportunities to answer many including the extent of host system reliance on defensive symbionts, the role of competition among symbionts, or the potential co-diversification of defensive symbionts with parasites.

In vertebrates, emerging evidence shows that microbes inhabiting many sites in the body have a role in maintaining health even though few studies examine the direct role of defensive symbionts in resistance against parasites. Promising experimental systems include the red-back salamander, Plethodon cinereus that hosts cutaneous, antifungal metaboliteproducing bacteria, which prevent infection by pathogenic fungi Batrachochytrium dendrobatidis (Brucker et al., 2007, 2008). In birds, Upupa epops and Phoeniculus purpureus, the uropygial glands house symbiotic bacteria that secrete protective antimicrobial substances providing protection to the feathers and eggs (Martín-Platero et al., 2006; Ruiz-Rodriguez et al., 2009; Martín-Vivaldi et al., 2010, 2014; Ruiz-Rodríguez et al., 2013). Further studies of these tractable vertebrate biological systems are necessary to characterize the significance of the increased 


\title{
Contribution of the host microbiome to the host fitness \\ Production of toxins \\ Maturation of the immune system
}

Stimulation of the immune system

\author{
Evolutionary response from the parasite \\ Disruption of the host microbiome \\ Avoidance of symbiotic hosts
}

Evolutionary response from the host

Recognition of the parasite microbiome

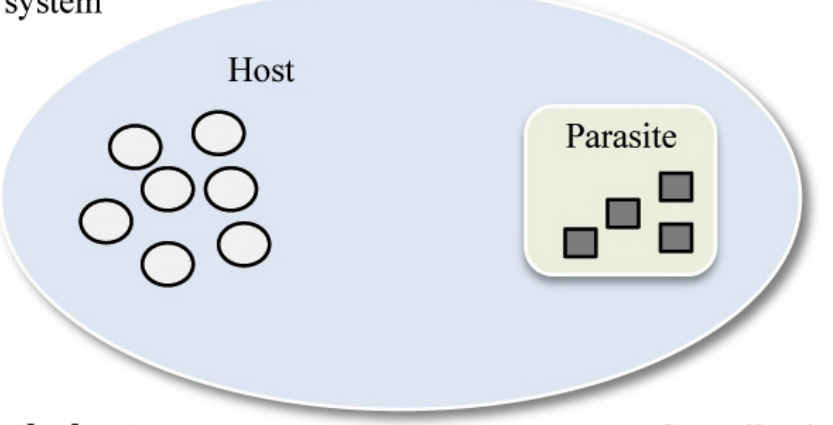

Contribution of the parasite microbiome to the parasite fitness

Production of toxins

Increased virulence

Redirect the host immune system

FIGURE 1 | Contribution of the host and parasite microbiome to the host and parasite fitness and evolutionary responses expected from the parasite and host, respectively. The smaller symbols represent the microbes; the shape and color indicate whether it is associated with the host (white circle) or parasite (gray square).

resistance and test ecological and evolutionary theories that are mostly developed on invertebrate systems.

\section{PARASITE DISRUPTIVE STRATEGIES}

Many parasites share the same environment as host-associated microbes, including defensive symbionts. Interestingly, parasites from all major phyla, including helminthes, viruses, bacteria, and fungi modify their host microbiome. For example, parasitic helminth infection results in significant modifications of gut microbiome in humans, pigs, cattle, hamsters, goats, and sheep (Nicholls, 1987; Li et al., 2011, 2012, 2016; Wu et al., 2012; Plieskatt et al., 2013; Cantacessi et al., 2014; Lee et al., 2014). But it is unknown if the modifications in the composition of the host microbiome are beneficial for the parasite, a defense mechanism of the host, or by-products of the pathology. It was proposed that parasites can directly modify their microbial environment to make it more favorable, or to exercise immune-modulatory activity and reduce the host resistance to infection, a process called the disruptive strategy (Dheilly et al., 2015b). In helminths, evidence suggests that alteration of the host microbiome indeed participates in parasite strategies to modulate the host immune system (Plieskatt et al., 2013). This theory is also supported by the observation that hatching by the nematode Trichuris muris is dependent on an abundant microflora (Hayes et al., 2010; Kane et al., 2011; Kuss et al., 2011) but the beneficial role of parasite-associated disruption of the host microbiome remains to be experimentally tested in a tractable system. Trophically transmitted parasites such as cestodes, are of interest because they have the potential to interact with microbes associated with both definitive and intermediate hosts. Triaenophorus nodulosus and Eubortium rugosum have been found to physically interact with many gut bacteria of their intermediate hosts, Esox Lucius (pike) and Lota lota (burbot), respectively, (Izvekova and Lapteva, 2004). In the rat, Hymenolepis diminuta infection results in a significant modification of the gut microbiome composition and a stronger stability in response to a mild inflammatory challenge (McKenney et al., 2015). The cestode parasite, Schistocephalus solidus, appears as a model of choice to investigate cestode parasite interactions with host gut microbes because all parasite stages can be cultured in vitro by mimicking either the avian intestinal environment, or the copepod or the stickleback fish body cavity (Smyth, 1990; Jakobsen et al., 2012), which allows rigorous functional experiments. Of interest, the highly specific second intermediate host of $S$. solidus, the threespine stickleback has a broad geographical variation (Hagen and Gilbertson, 1972) and has become a model species in biology for both ecological and evolutionary studies of the interaction (Barber and Nettleship, 2010).

While most microbiome disruptions by parasites result in subtle changes with unknown consequences for the outcome of infection, some have spectacular consequences. Vibrio shiloi, a bacterium infecting the coral host Oculina patagonica, produces toxins specifically targeting the coral's symbiotic zooxanthellae (Kushmaro et al., 1997, 1998, 2001). Following the temperaturedependent attachment to the coral surface, $V$. shiloi infiltrates 
the tissue and multiplies rapidly (Kushmaro et al., 1998; Toren et al., 1998; Banin et al., 2000). The bacterium then releases photosynthesis-inhibiting toxins and lyses zooxanthellae, eventually leading to coral bleaching and death (Ben-Haim et al., 1999). In another key example, the microsporidian parasite Paranosema locustae relies on gut acidification of its locust host (Locusta migratoria manilensis) and increased production of reactive oxygen species to modify the gut microbial community and insure its own development (Shi et al., 2014). Because the locust microbiome is involved in producing pheromones responsible for the locust swarming behavior, infection by P. locustae prevents swarming (Dillon et al., 2000; Shi et al., 2014). The adaptive value and specificity of $V$. shiloi and $P$. locustae for their host-associated microbes remain to be demonstrated but the obvious phenotypic changes associated with the microbiome disruption increases the value of these organismal systems. In addition, they provide the opportunity to study evolutionary trade-offs of parasite induced disruption of the host microbiome.

\section{PARASITE BIOLOGICAL WEAPON STRATEGIES}

The presence of microbes associated with hosts has been demonstrated in many systems, but the presence of microbes associated with parasites has been tested less frequently. For example, Wolbachia is an obligate bacterial symbiont of parasitic filarial nematodes (Kozek, 1977; Hoerauf et al., 1999). Wolbachia incite inflammatory reactions in the human host and it has been implicated in many debilitating diseases (Taylor and Hoerauf, 1999). For instance, Wolbachia-induced inflammation is responsible for the loss of vision and blindness following O. volvulus infection (Francis et al., 1985; Hall and Pearlman, 1999; Saint André et al., 2002) and for the inflammation of lymphatic vessels following $W$. bancrofti infection (Dreyer et al., 2000; Hoerauf et al., 2003). Similarly, the trematode Opisthorchis viverrini, also known as liver fluke, often leads to cholangiocarcinoma (Braconi and Patel, 2010). Recent studies demonstrated that $O$. viverrini is associated with a complex microbiome (Plieskatt et al., 2013) and that some of these bacteria are transmitted to the host and present in abundance in tumors, calling for more basic experiments to determine their contribution in cancer development (Chng et al., 2016; Osborne and WegenerParfrey, 2016). Other parasites are associated with viruses, such as Trichomonas vaginalis, a protozoan parasite that infects the human vagina (Goodman et al., 2011). Approximately half of all clinical samples carry a dsRNA virus called Trichomonavirus that is recognized by the human immune system and causes an inflammatory response (Fichorova et al., 2012) responsible for increased susceptibility to sexually transmitted diseases (Van Der Pol et al., 2008), infertility (Grys, 1972; Grodstein et al., 1993), miscarriage (Minkoff et al., 1984), pre-term delivery (Hardy et al., 1984; Minkoff et al., 1984), low birth weight (Hardy et al., 1984), and cervical cancer (Gram et al., 1992; Kharsany et al., 1993). The presence of the Trichomonavirus also explains why symptoms can worsen upon successful antibiotic treatment: the dying parasite releases its viral load within the human vagina (Fichorova et al., 2012). Notably, parasites from various phyla are associated with viruses, including trematodes and parasitic protozoans but their impact on the host has been rarely investigated (Ip and Desser, 1984; Wang and Wang, 1991; Ives et al., 2011). Clearly, the significance of parasite-virus and parasite-bacteria associations for treatment of the diseases is evident. But, what is the significance of the phenomenon for the parasites themselves? It has been proposed that parasites can utilize symbionts to increase their virulence, a process called the biological weapon strategy (Dheilly et al., 2015b). Clearly, further experimental studies are needed to determine if symbiotic bacteria or viruses and associated inflammation are beneficial for the parasite.

A promising tractable experimental system involves the parasitoid wasp, Dinocampus coccinellae that infects ladybeetles and carries a RNA virus, D. coccinellae paralysis virus (DcPV; Dheilly et al., 2015a). In adult wasps, DcPV is stored in the oviduct. The wasp injects its eggs into the body cavity of the ladybeetle and the growing larvae feed off the ladybeetle's fat body. During larval development, the virus replicates actively and is transmitted to the ladybeetle. DcPV then targets the ladybeetle nervous tissue. When later a single mature larva egresses from the host, DcPV replication in the ladybeetle nervous system results in the induction of antiviral immune responses and damage to the nervous tissue associated with ladybeetle paralysis. The larva stills between the legs of the immobilized ladybeetle and spins a cocoon within which it pupates into an adult wasp. The ladybeetle appears crouched protectively over the cocoon of the wasp and makes erratic movements efficiently deterring predators (Maure et al., 2011). Upon larva pupation, clearance of DcPV and nervous system regeneration results in the ladybeetle recovery of normal behavior (Dheilly et al., 2015a). Therefore, it appears that D. coccinellae uses DcPV as a biological weapon to manipulate its ladybeetle host and protect its progeny from predation (Maure et al., 2011; Dheilly et al., 2015a). This organismal system appears ideal to investigate the role of associated viruses in the evolution of parasites because of the short generation time of host and parasite, the broad geographic range of the parasite that infect ladybeetle species on all continents, and because of the possibility to track variations in virus genome in experimental evolution experiments. Most interestingly, ladybeetles are also associated with a diverse array of bacteria including multiple members of the genus Flavobacteria, Rickettsia, Spiroplasma, and Wolbachia, that may be involved in ladybeetle defense against the parasitoid (Hurst et al., 1994, 1997; Weinert et al., 2007; Elnagdy et al., 2013). Using techniques developed previously to study the defensive role of aphid symbionts, the microbiome of ladybeetles could be manipulated using a combination of antibiotic treatments and microinjections. Thus, this organismal system provides an opportunity to investigate the possibility for direct interactions between host-associated microbes and parasite-associated microbes within the body cavity of the host. 
BOX 1 | Key Criteria for experimental model evaluation.

(1) The host and parasite could be bred and maintained in the laboratory. It is a necessary step to perform controlled experimental infections and understand the transmission mechanisms of symbionts of interest. It is also crucial for testing the environmental and host genetic factors that regulate the abundance, diversity and stability of the microbiome.

(2) A core microbiome would have been identified in the host suggesting that it selects for specific microbes. This in itself suggests that the host should be considered as a holobiont.

(3) The parasite shares the same environment as microbes in the host body, which would suggest potential direct parasite-host-associated microbe interaction that remain to be tested.

(4) The parasite would be associated with microbes for which the role in virulence will be assessed. The presence of a core microbiome in parasites and the role of parasite-associated microbes in driving the evolution of host defenses remain to be demonstrated.

(5) Techniques have been developed to manipulate the composition of the microbiome of the host and/or parasite. The role of microbes in the result of infection can only be tested through manipulation of the microbiome and injection of isolated microbes. It is necessary to characterize the role of microbes individually and as a community in susceptibility, resistance, and infectivity.

(6) The host and the parasite would have a wide geographical species range and ecological diversity, which would allow comprehensive fields studies to understand how environmental factors influence host-parasite-microbe interaction. It would allow to examine the role of microbes in local adaptation of parasites through cross-infection experiments.

(7) The host and/or parasite would have short generation time, which would facilitate the use experimental evolution to test the role of microbes in host or parasite adaptation. For instance, the hologenome theory would predict that associated microbes participate in the arms race through shorter generation time and higher mutation rate but this hypothesis remains to be tested.

(8) Closely related species of hosts could be parasitized with closely related species of parasites, thus allowing comparative studies of the role of microbes in the interaction and testing their role during parasite evolution, host switch, and host or parasite speciation.

(9) The parasite would have various effects on the phenotype of its host, so that the role of microbes in any aspect of the 'normal' behavior or appearance of infected organism may be more readily detected and more reliably assessed for fitness consequences.

(10) The genome of the host and parasite would have been sequenced, facilitating the use of high throughput comparative genomics approaches to characterize the genes involved in

\section{CONCLUSION}

Understanding the role of microbes in host and parasite ecology and evolution is important for both basic and applied biology, as so many disease-causing organisms carry their own microbes or interact with host-associated microbes. Empirical studies of host-parasite-microbes interactions at a mechanistic and evolutionary level can help us understand the ecological circumstances where symbiosis benefits host or parasite fitness. The current review of experimental systems enabling studies of host-parasite-microbe interactions has allowed us to identify key criteria to improve upon and further study these complex interactions (Box 1, Supplementary Table S1). We would like to emphasize that it is now crucial to investigate the role of community of microbes as well as individual microbial symbionts. Indeed, microbes may independently, synergistically, or antagonistically impact and participate in the physiology and evolution of their hosts Therefore, it is of particular importance to develop models where it is possible to intimately manipulate the host and parasite microbiomes to alter their composition. We expect that future research project will couple such manipulation with new sequencing technologies, proteomics or metabolomics to elucidate the molecular dialog between the different partners, as demonstrated in studies of host-symbiont and host-microbiome interactions (Chaston and Douglas, 2012; Rooks and Garrett, 2016). Development of these systems can provide a basis for developing new therapeutic and prevention strategies: vector hosts could be inoculated with defensive symbionts to reduce the transmission rate of a parasite;
Parasite-associated microbes could be targeted to limit parasite development and allow its elimination by the host immune system; New parasite-specific probiotics could be selected to increase resistance or tolerance to parasitic infection. Developing these experimental systems for host-parasitemicrobes' interactions is now critical to determine which partner in the interaction should be targeted for effective therapy. Finally, investigating the role of microbes and microbiomes in host-parasite interactions may provide opportunities to confirm or infirm the hologenome theory of evolution by demonstrating multi-level selection.

\section{AUTHOR CONTRIBUTIONS}

All authors listed, have made substantial, direct and intellectual contribution to the work, and approved it for publication.

\section{FUNDING}

The authors acknowledge support from Stony Brook University.

\section{SUPPLEMENTARY MATERIAL}

The Supplementary Material for this article can be found online at: http://journal.frontiersin.org/article/10.3389/fmicb.2016. 01300 


\section{REFERENCES}

Banin, E., Israely, T., Kushmaro, A., Loya, Y., Orr, E., and Rosenberg, E. (2000). Penetration of the coral-bleaching bacterium Vibrio shiloi into Oculina patagonica. Appl. Environ. Microbiol. 66, 3031-3036. doi: 10.1128/AEM.66.7.3031-3036.2000

Barber, I., and Nettleship, S. (2010). From 'trash fish'to supermodel: the rise and rise of the three-spined stickleback in evolution and ecology. Biologist 57, 15-21.

Benson, A., Pifer, R., Behrendt, C. L., Hooper, L. V., and Yarovinsky, F. (2009). Gut commensal bacteria direct a protective immune response against Toxoplasma gondii. Cell Host Microbe 6, 187-196. doi: 10.1016/j.chom.2009.06.005

Ben-Haim, Y., Banim, E., Kushmaro, A., Loya, Y., and Rosenberg, E. (1999). Inhibition of photosynthesis and bleaching of zooxanthellae by the coral pathogen Vibrio shiloi. Appl. Environ. Microbiol. 1, 223-229. doi: 10.1046/j.1462-2920.1999.00027.x

Bian, G., Xu, Y., Lu, P., Xie, Y., and Xi, Z. (2010). The endosymbiotic bacterium Wolbachia induces resistance to dengue virus in Aedes aegypti. PLoS Pathog. 6:e1000833. doi: 10.1371/journal.ppat.1000833

Bordenstein, S. R., and Theis, K. R. (2015). Host biology in light of the microbiome: ten principles of holobionts and hologenomes. PLoS Biol. 13:e1002226. doi: 10.1371/journal.pbio.1002226

Braconi, C., and Patel, T. (2010). Cholangiocarcinoma: new insights into disease pathogenesis and biology. Infect. Dis. Clin. North Am. 24, 871-884. doi: 10.1016/j.idc.2010.07.006

Bronstein, J. L. (2009). The evolution of facilitation and mutualism. J. Ecol. 97, 1160-1170. doi: 10.1111/j.1365-2745.2009.01566.x

Brucker, R. M., Baylor, C. M., Walters, R. L., Lauer, A., Harris, R. N., and Minbiole, K. P. C. (2007). The identification of 2,4-diacetylphloroglucinol as an antifungal metabolite produced by cutaneous bacteria of the salamander Plethodon cinereus. J. Chem. Ecol. 34, 39-43. doi: 10.1007/s10886-0079352-8

Brucker, R. M., Harris, R. N., Schwantes, C. R., Gallaher, T. N., Flaherty, D. C., Lam, B. A., et al. (2008). Amphibian chemical defense: antifungal metabolites of the microsymbiont Janthinobacterium lividum on the salamander Plethodon cinereus. J. Chem. Ecol. 34, 1422-1429. doi: 10.1007/s10886-0089555-7

Buffie, C. G., and Pamer, E. G. (2013). Microbiota-mediated colonization resistance against intestinal pathogens. Nat. Rev. Immunol. 13, 790-801. doi: $10.1038 /$ nri3535

Cantacessi, C., Giacomin, P., Croese, J., Zakrzewski, M., Sotillo, J., McCann, L., et al. (2014). Impact of experimental hookworm infection on the human gut microbiota. J. Infect. Dis. 210, 1431-1434. doi: 10.1093/infdis/jiu256

Cash, H. L. (2006). The Ligand and Function of the RegIII Family of Bactericidal C-Type Lectins. Master's thesis, University of Texas Southwestern Medical Center, Dallas, TX.

Cayetano, L., Rothacher, L., Simon, J.-C., and Vorburger, C. (2015). Cheaper is not always worse: strongly protective isolates of a defensive symbiont are less costly to the aphid host. Proc. R. Soc.B 282, 20142333. doi: 10.1098/rspb.2014.2333

Chaston, J., and Douglas, A. (2012). Making the most of "omics" for symbiosis research. Biol. Bull. 223, 21-29.

Cheng, T. C. (2012). General Parasitology. Amsterdam: Elsevier.

Chng, K. R., Chan, S. H., Ng, A. H. Q., Li, C., Jusakul, A., Bertrand, D., et al. (2016). Tissue microbiome profiling identifies an enrichment of specific enteric bacteria in Opisthorchis viverrini associated cholangiocarcinoma. EBioMedicine 8, 195-202. doi: 10.1016/j.ebiom.2016.04.034

Clay, K. (1988). Fungal endophytes of grasses: a defensive mutualism between plants and fungi. Ecology 69, 10-16. doi: 10.2307/1943155

Cox, F. E. G. (2001). Concomitant infections, parasites and immune responses. Parasitology 122, S23-S38. doi: 10.1017/S003118200001698X

de Bary, A. (1879). Die Erscheinung der Symbiose: Vortrag gehalten auf der Versammlung Deutscher Naturforscher und Aerzte zu Cassel. Strassburg: Verlag von Karl J. Trübner.

Dheilly, N. M. (2014). Holobiont-Holobiont interactions: redefining host-parasite interactions. PLoS Pathog. 10:e1004093. doi: 10.1371/journal.ppat.1004093

Dheilly, N. M., Maure, F., Ravallec, M., Galinier, R., Doyon, J., Duval, D., et al. (2015a). Who is the puppet master? Replication of a parasitic waspassociated virus correlates with host behaviour manipulation. Proc. R. Soc. B 282, 20142773. doi: 10.1098/rspb.2014.2773
Dheilly, N. M., Poulin, R., and Thomas, F. (2015b). Biological warfare: microorganisms as drivers of host-parasite interactions. Infect. Genet. Evol. 34, 251-259. doi: 10.1016/j.meegid.2015.05.027

Dietert, R. R. (2016). The microbiome-immune-host defense barrier complex (microimmunosome) and developmental programming of noncommunicable diseases. Reprod. Toxicol. (in press). doi: 10.1016/j.reprotox.2016.04.026

Dillon, R. J., Vennard, C. T., and Charnley, A. K. (2000). Pheromones: exploitation of gut bacteria in the locust. Nature 403, 851-851. doi: 10.1038/35002669

Douglas, A. E., and Werren, J. H. (2016). Holes in the hologenome: why host-microbe symbioses are not holobionts. mBio 7, e02099. doi: 10.1128/mBio.02099-15

Dreyer, G., Noroes, J., Figueredo-Silva, J., and Piessens, W. (2000). Pathogenesis of lymphatic disease in bancroftian filariasis: a clinical perspective. Parasitol. Today. 16, 544-548. doi: 10.1016/S0169-4758(00)01778-6

Elnagdy, S., Messing, S., and Majerus, M. E. N. (2013). Two strains of male-killing Wolbachia in a ladybird, Coccinella undecimpunctata, from a hot climate. PLoS ONE 8:e54218. doi: 10.1371/journal.pone.0054218

Fichorova, R. N., Lee, Y., Yamamoto, H. S., Takagi, Y., Hayes, G. R., Goodman, R. P., et al. (2012). Endobiont viruses sensed by the human host-beyond conventional antiparasitic therapy. PLoS ONE 7:e48418. doi: 10.1371/journal.pone. 0048418

Francis, H., Awadzi, K., and Ottesen, E. (1985). The Mazzotti reaction following treatment of onchocerciasis with diethylcarbamazine: clinical severity as a function of infection intensity. Am. J. Trop. Med. Hyg. 34, 529-536.

Fry, A. J., Palmer, M. R., and Rand, D. M. (2004). Variable fitness effects of Wolbachia infection in Drosophila melanogaster. Heredity (Edinb) 93, 379-389. doi: 10.1038/sj.hdy.6800514

Glaser, R. L., and Meola, M. A. (2010). The native Wolbachia endosymbionts of Drosophila melanogaster and Culex quinquefasciatus increase host resistance to West Nile virus infection. PLoS ONE 5:e11977. doi: 10.1371/journal.pone.0011977

Gollwitzer, E. S., and Marsland, B. J. (2015). Impact of early-life exposures on immune maturation and susceptibility to disease. Trends Immunol. 36, 684696. doi: 10.1016/j.it.2015.09.009

Goodman, R. P., Ghabrial, S. A., Fichorova, R. N., and Nibert, M. L. (2011). Trichomonasvirus: a new genus of protozoan viruses in the family Totiviridae. Arch. Virol. 156, 171-179. doi: 10.1007/s00705-010-0832-8

Gram, I. T., Macaluso, M., Churchill, J., and Stalsberg, H. (1992). Trichomonas vaginalis (TV) and human papillomavirus (HPV) infection and the incidence of cervical intraepithelial neoplasia (CIN) grade III. Cancer Causes Control 3, 231-236. doi: 10.1007/BF00124256

Grodstein, F., Goldman, M. B., and Cramer, D. W. (1993). Relation of tubal infertility to history of sexually transmitted diseases. Am. J. Epidemiol. 137, 577-584.

Grys, E. (1972). Diagnosis of trichomonadosis in the urinary tract of women (preliminary report). Ann. Parasitol. 19, 461-462.

Hagen, D., and Gilbertson, L. (1972). Geographic variation and environmental selection in Gasterosteus aculeatus L. in the Pacific Northwest, America. Evolution 26, 32-51. doi: 10.2307/2406981

Hall, J. A., Bouladoux, N., Sun, C. M., Wohlfert, E. A., Blank, R. B., Zhu, Q., et al. (2008). Commensal DNA limits regulatory $\mathrm{T}$ cell conversion and is a natural adjuvant of intestinal immune responses. Immunity 29, 637-649. doi: 10.1016/j.immuni.2008.08.009

Hall, L. R., and Pearlman, E. (1999). Pathogenesis of onchocercal keratitis (river blindness). Clin. Microbiol. Rev. 12, 445-453.

Hardy, P., Nell, E. E., Spence, M., Hardy, J., Graham, D., and Rosenbaum, R. (1984). Prevalence of six sexually transmitted disease agents among pregnant inner-city adolescents and pregnancy outcome. Lancet. 324, 333-337. doi: 10.1016/S0140-6736(84)92698-9

Hayes, K., Bancroft, A., Goldrick, M., Portsmouth, C., Roberts, I., and Grencis, R. (2010). Exploitation of the intestinal microflora by the parasitic nematode Trichuris muris. Science 328, 1391-1394. doi: 10.1126/science. 1187703

Hedges, L. M., Brownlie, J. C., O’Neill, S. L., and Johnson, K. N. (2008). Wolbachia and virus protection in insects. Science 322, 702-702. doi: 10.1126/science.1162418

Hoerauf, A., Mand, S., Volkmann, L., Büttner, M., Marfo-Debrekyei, Y., Taylor, M., et al. (2003). Doxycycline in the treatment of human onchocerciasis: kinetics 
of Wolbachia endobacteria reduction and of inhibition of embryogenesis in female Onchocerca worms. Microbes Infect. 5, 261-273. doi: 10.1016/S12864579(03)00026-1

Hoerauf, A., Nissen-Pähle, K., Schmetz, C., Henkle-Dührsen, K., Blaxter, M. L., Büttner, D. W., et al. (1999). Tetracycline therapy targets intracellular bacteria in the filarial nematode Litomosoides sigmodontis and results in filarial infertility. J. Clin. Invest. 103, 11-18. doi: 10.1172/JCI4768

Hoffmann, A., Montgomery, B., Popovici, J., Iturbe-Ormaetxe, I., Johnson, P., Muzzi, F., et al. (2011). Successful establishment of Wolbachia in Aedes populations to suppress dengue transmission. Nature 476, 454-457. doi: 10.1038 /nature 10356

Hurst, G. D. D., Hammarton, T. C., Bandi, C., Majerus, T. M. O., Bertrand, D., and Majerus, M. E. N. (1997). The diversity of inherited parasites of insects: the male-killing agent of the ladybird beetle Coleomegilla maculata is a member of the Flavobacteria. Genet. Res. 70, 1-6. doi: 10.1017/S001667239700 2838

Hurst, G. D. D., Purvis, E. L., Sloggett, J. J., and Majerus, M. E. N. (1994). The effect of infection with male-killing Rickettsia on the demography of female Adalia bipunctata L. (two spot ladybird). Heredity 73, 309-316. doi: 10.1038/hdy.1994.138

Ip, H. S., and Desser, S. S. (1984). A picornavirus-like pathogen of Cotylogaster occidentalis (Trematoda: Aspidogastrea), an intestinal parasite of freshwater mollusks. J. Invertebr. Pathol. 43, 197-206. doi: 10.1016/0022-2011(84) 90138-1

Iturbe-Ormaetxe, I., Walker, T., and O' Neill, S. L. (2011). Wolbachia and the biological control of mosquito-borne disease. EMBO Rep. 12, 508-518. doi: 10.1038/embor.2011.84

Ives, A., Ronet, C., Prevel, F., Ruzzante, G., Fuertes-Marraco, S., Schutz, F., et al. (2011). Leishmania RNA virus controls the severity of Mucocutaneous leishmaniasis. Science 331, 775-778. doi: 10.1126/science.1199326

Izvekova, G., and Lapteva, N. (2004). Microflora associated with the digestivetransport surfaces of fish and their parasitic cestodes. Russ. J. Ecol. 35, 176-180. doi: 10.1023/B:RUSE.0000025968.97632.30

Jakobsen, P., Scharsack, J., Hammerschmidt, K., Deines, P., Kalbe, M., and Milinski, M. (2012). In vitro transition of Schistocephalus solidus (Cestoda) from coracidium to procercoid and from procercoid to plerocercoid. Exp. Parasitol. 130, 267-273. doi: 10.1016/j.exppara.2011.09.009

Kamada, N., Kim, Y.-G., Sham, H. P., Vallance, B. A., Puente, J. L., Martens, E. C., et al. (2012). Regulated virulence controls the ability of a pathogen to compete with the gut microbiota. Science 336, 1325-1329. doi: 10.1126/science. 1222195

Kane, M., Case, L. K., Kopaskie, K., Kozlova, A., MacDearmid, C., Chervonsky, A. V., et al. (2011). Successful transmission of a retrovirus depends on the commensal microbiota. Science 334, 245-249. doi: 10.1126/science. 1210718

Kharsany, A., Hoosen, A., Moodley, J., Bagaratee, J., and Gouws, E. (1993). The association between sexually transmitted pathogens and cervical intra-epithelial neoplasia in a developing community. Genitourin. Med. 69, 357-360. doi: 10.1136/sti.69.5.357

King, K. C., Brockhurst, M. A., Vasieva, O., Paterson, S., Betts, A., Ford, S. A., et al. (2016). Rapid evolution of microbe-mediated protection against pathogens in a worm host. ISME J. 10, 1915-1924. doi: 10.1038/ismej.2015.259

Kloetzel, K., Chieffi, P., and Faleiros, J. (1977). Mortality and other parameters of concomitant infections in albino mice: the Schistosoma-Toxoplasma model. Trop. Geogr. Med. 29, 407-410.

Kloetzel, K., Faleiros, J. J., and Mendes, S. R. (1971). Concurrent infection of white mice with T. cruzi and S. mansoni. Trans. R. Soc. Trop. Med. Hyg. 65, 530-531. doi: 10.1016/0035-9203(71)90167-2

Kozek, W. J. (1977). Transovarially-transmitted intracellular microorganisms in adult and larval stages of Brugia malayi. J. Parasitol. 63, 992-1000. doi: $10.2307 / 3279832$

Kushmaro, A., Banin, E., Loya, Y., Stackebrandt, E., and Rosenberg, E. (2001). Vibrio shiloi sp. nov., the causative agent of bleaching of the coral Oculina patagonica. Int. J. Syst. Evol. Microbiol. 51, 1383-1388. doi: 10.1099/0020771351-4-1383

Kushmaro, A., Rosenberg, E., Fine, M., Ben Haim, Y., and Loya, Y. (1998). Effect of temperature on bleaching of the coral Oculina patagonica by Vibrio AK-1. Mar. Ecol. Prog. Ser. 171, 131-137. doi: 10.3354/meps171131
Kushmaro, A., Rosenberg, E., Fine, M., and Loya, Y. (1997). Bleaching of the coral Oculina patagonica by Vibrio AK-1. Mar. Ecol. Prog. Ser. 147, 159-165. doi: 10.3354/meps147159

Kuss, S. K., Best, G. T., Etheredge, C. A., Pruijssers, A. J., Frierson, J. M., Hooper, L. V., et al. (2011). Intestinal microbiota promote enteric virus replication and systemic pathogenesis. Science 334, 249-252. doi: 10.1126/science.1211057

Kwiatkowski, M., Engelstädter, J., and Vorburger, C. (2012). On genetic specificity in symbiont-mediated host-parasite coevolution. PLoS Comput. Biol. 8:e1002633. doi: 10.1371/journal.pcbi.1002633

Lee, S. C., San Tang, M., Lim, Y. A., Choy, S. H., Kurtz, Z. D., Cox, L. M., et al. (2014). Helminth colonization is associated with increased diversity of the gut microbiota. PLoS Negl. Trop. Dis. 8:e2880. doi: 10.1371/journal.pntd. 0002880

Li, R. W., Li, W., Sun, J., Yu, P., Baldwin, R. L., and Urban, J. F. (2016). The effect of helminth infection on the microbial composition and structure of the caprine abomasal microbiome. Sci. Rep. 6:20606. doi: 10.1038/srep20606

Li, R. W., Wu, S., Li, W., Huang, Y., and Gasbarre, L. C. (2011). Metagenome plasticity of the bovine abomasal microbiota in immune animals in response to Ostertagia ostertagi infection. PLoS ONE 6:e24417. doi: 10.1371/journal.pone.0024417

Li, R. W., Wu, S., Li, W., Navarro, K., Couch, R. D., Hill, D., et al. (2012). Alterations in the porcine colon microbiota induced by the gastrointestinal nematode Trichuris suis. Infect. Immun. 80, 2150-2157. doi: 10.1128/IAI. 00141-12

Margulis, L. (1991). "Symbiogenesis and Symbionticism," in Symbiosis as a Source of Evolutionary Innovation: Speciation and Morphogenesis, eds L. Margulis and R. Fester (Cambridge, MA: MIT Press), 1-13.

Martinez, J., Cogni, R., Cao, C., Smith, S., Illingworth, C. J., and Jiggins, F. M. (2016a). Addicted? Reduced host resistance in populations with defensive symbionts. Proc. R. Soc. B 283, 20160778. doi: 10.1098/rspb.2016.0778

Martinez, A. J., Kim, K. L., Harmon, J. P., and Oliver, K. M. (2016b). Specificity of multi-modal aphid defenses against two rival parasitoids. PLoS ONE 11:e0154670. doi: 10.1371/journal.pone.0154670

Martín-Platero, A. M., Valdivia, E., Ruíz-Rodríguez, M., Soler, J. J., MartínVivaldi, M., Maqueda, M., et al. (2006). Characterization of antimicrobial substances produced by Enterococcus faecalis MRR 10-3, isolated from the uropygial gland of the hoopoe (Upupa epops). Appl. Environ. Microbiol. 72, 4245-4249. doi: 10.1128/AEM.02940-05

Martín-Vivaldi, M., Peña, A., Peralta-Sánchez, J. M., Sánchez, L., Ananou, S., Ruiz-Rodríguez, M., et al. (2010). Antimicrobial chemicals in hoopoe preen secretions are produced by symbiotic bacteria. Proc. R. Soc. B 277, 123-130. doi: 10.1098/rspb.2009

Martín-Vivaldi, M., Soler, J. J., Peralta-Sánchez, J. M., Arco, L., Martín-Platero, A. M., Martínez-Bueno, M., et al. (2014). Special structures of hoopoe eggshells enhance the adhesion of symbiont-carrying uropygial secretion that increase hatching success. J. Anim. Ecol. 83, 1289-1301. doi: 10.1111/1365-2656. 12243

Maure, F., Brodeur, J., Ponlet, N., Doyon, J., Firlej, A., Elguero, É, et al. (2011). The cost of a bodyguard. Biol. Lett. 7, 843-846. doi: 10.1098/rsbl.2011.0415

McKenney, E. A., Williamson, L., Yoder, A. D., Rawls, J. F., Bilbo, S. D., and Parker, W. (2015). Alteration of the rat cecal microbiome during colonization with the helminth Hymenolepis diminuta. Gut Microbes 6, 182-193. doi: $10.1080 / 19490976.2015 .1047128$

Minkoff, H., Grunebaum, A. N., Schwarz, R. H., Feldman, J., Cummings, M., Crombleholme, W., et al. (1984). Risk factors for prematurity and premature rupture of membranes: a prospective study of the vaginal flora in pregnancy. Am. J. Obstet. Gynecol. 150, 965-972. doi: 10.1016/0002-9378(84)90392-2

Moran, N. A., and Sloan, D. B. (2015). The hologenome concept: helpful or hollow? PLoS Biol. 13:e1002311. doi: 10.1371/journal.pbio.1002311

Moreira, L. A., Iturbe-Ormaetxe, I., Jeffery, J. A., Lu, G., Pyke, A. T., Hedges, L. M., et al. (2009). A Wolbachia symbiont in Aedes aegypti limits infection with dengue, Chikungunya, and Plasmodium. Cell 139, 1268-1278. doi: 10.1016/j.cell.2009.11.042

Nicholls, C. (1987). Endoscopy, Physiology and Bacterial Flora of Sheep Infected with Abomasal Nematodes. Ph.D. thesis, University of Leeds, Leeds.

Oliver, K. M., Campos, J., Moran, N. A., and Hunter, M. S. (2008). Population dynamics of defensive symbionts in aphids. Proc. R. Soc. B 275, 293-299. doi: $10.1098 /$ rspb.2007.1192 
Oliver, K. M., Moran, N. A., and Hunter, M. S. (2005). Variation in resistance to parasitism in aphids is due to symbionts not host genotype. Proc. Natl. Acad. Sci. 102, 12795-12800. doi: 10.1073/pnas.0506131102

Oliver, K. M., Noge, K., Huang, E. M., Campos, J. M., Becerra, J. X., and Hunter, M. S. (2012). Parasitic wasp responses to symbiont-based defense in aphids. BMC Biol. 10:11. doi: 10.1186/1741-7007-10-11

Oliver, K. M., Russell, J. A., Moran, N. A., and Hunter, M. S. (2003). Facultative bacterial symbionts in aphids confer resistance to parasitic wasps. Proc. Natl. Acad. Sci. 100, 1803-1807. doi: 10.1073/pnas.0335320100

Oliver, K. M., Smith, A. H., and Russell, J. A. (2014). Defensive symbiosis in the real world-advancing ecological studies of heritable, protective bacteria in aphids and beyond. Funct. Ecol. 28, 341-355. doi: 10.1111/1365-2435.12133

Osborne, L. C., and WegenerParfrey, L. (2016). Liver flukes and the microbiota in cancer. EBioMedicine 8, 12-13. doi: 10.1016/j.ebiom.2016.05.038

Osborne, S. E., Leong, Y. S., O’Neill, S. L., and Johnson, K. N. (2009). Variation in antiviral protection mediated by different Wolbachia strains in Drosophila simulans. PLoS Pathog. 5:e1000656. doi: 10.1371/journal.ppat. 1000656

Plieskatt, J. L., Deenonpoe, R., Mulvenna, J. P., Krause, L., Sripa, B., Bethony, J. M., et al. (2013). Infection with the carcinogenic liver fluke Opisthorchis viverrini modifies intestinal and biliary microbiome. FASEB J. 27, 4572-4584. doi: 10.1096/fj.13-232751

Polin, S., Simon, J. C., and Outreman, Y. (2014). An ecological cost associated with protective symbionts of aphids. Ecol. evol. 4, 836-840. doi: 10.1002/ece3.991

Rooks, M. G., and Garrett, W. S. (2016). Gut microbiota, metabolites and host immunity. Nat. Rev. Immunol. 16, 341-352. doi: 10.1038/nri.2016.42

Rosenberg, E., and Zilber-Rosenberg, I. (2011). “The Hologenome Concept," in Beneficial Microorganisms in Multicellular Life Forms, eds E. Rosenberg and U. Gophna (Berlin: Springer), 323-340.

Rothacher, L., Ferrer-Suay, M., and Vorburger, C. (2016). Bacterial endosymbionts protect aphids in the field and alter parasitoid community composition. Ecology 97, 1712-1723. doi: 10.1890/15-2022.1

Ruiz-Rodríguez, M., Martínez-Bueno, M., Martín-Vivaldi, M., Valdivia, E., and Soler, J. J. (2013). Bacteriocins with a broader antimicrobial spectrum prevail in enterococcal symbionts isolated from the hoopoe's uropygial gland. FEMS Microbiol. Ecol. 85, 495-502. doi: 10.1111/1574-6941.12138

Ruiz-Rodriguez, M., Valdivia, E., Soler, J. J., Martin-Vivaldi, M., Martin-Platero, A., and Martinez-Bueno, M. (2009). Symbiotic bacteria living in the hoopoe's uropygial gland prevent feather degradation. J. Exp. Biol. 212, 3621-3626. doi: 10.1242/jeb.031336

Saint André, A. V., Blackwell, N. M., Hall, L. R., Hoerauf, A., Brattig, N. W., Volkmann, L., et al. (2002). The role of endosymbiotic Wolbachia bacteria in the pathogenesis of river blindness. Science 295, 1892-1895. doi: 10.1126/science. 1068732

Scarborough, C. L., Ferrari, J., and Godfray, H. (2005). Aphid protected from pathogen by endosymbiont. Science 310, 1781-1781. doi: 10.1126/science. 1120180

Shi, W., Guo, Y., Xu, C., Tan, S., Miao, J., Feng, Y., et al. (2014). Unveiling the mechanism by which microsporidian parasites prevent locust swarm behavior. Proc. Nat. Acad. Sci. U.S.A 111, 1343-1348. doi: 10.1073/pnas.13140 09111

Smyth, J. D. (1990). In Vitro Cultivation Of Parasitic Helminths. Boca Raton, FL: CRC press.

Taylor, M., and Hoerauf, A. (1999). Wolbachia bacteria of filarial nematodes. Parasitol. Today 15, 437-442. doi: 10.1016/S0169-4758(99)01533-1

Teixeira, L., Ferreira, Á., and Ashburner, M. (2008). The bacterial symbiont Wolbachia induces resistance to RNA viral infections in Drosophila melanogaster. PLoS Biol. 6:e1000002. doi: 10.1371/journal.pbio.1000002

Theis, K., Dheilly, N., Klassen, J., Brucker, R. M., Bosch, T. C. G., Cryan, J. F., et al. (2016). Getting the hologenome concept right: an eco-evolutoinary framework for hosts and their microbiome. mSystems 1. doi: 10.1128/mSystems. 00028-16

Toren, A., Landau, L., Kushmaro, A., Loya, Y., and Rosenberg, E. (1998). Effect of temperature on adhesion of Vibrio strain AK-1 to Oculina patagonica and on coral bleaching. Appl. Environ. Microbiol. 64, 1379-1384.

Van den Hurk, A. F., Hall-Mendelin, S., Pyke, A. T., Frentiu, F. D., McElroy, K., Day, A., et al. (2012). Impact of Wolbachia on infection with chikungunya and yellow fever viruses in the mosquito vector Aedes aegypti. PLoS Negl. Trop. Dis. 6:e1892. doi: 10.1371/journal.pntd.0001892

Van Der Pol, B., Kwok, C., Pierre-Louis, B., Rinaldi, A., Salata, R. A., Chen, P.L., et al. (2008). Trichomonas vaginalis infection and human immunodeficiency virus acquisition in African women. J. Infect. Dis. 197, 548-554. doi: 10.1086/ 526496

Vorburger, C., Ganesanandamoorthy, P., and Kwiatkowski, M. (2013). Comparing constitutive and induced costs of symbiont-conferred resistance to parasitoids in aphids. Ecol. evol. 3, 706-713. doi: 10.1002/ece3.491

Wang, A., and Wang, C. (1991). Viruses of the protozoa. Annu. Rev. Microbiol. 45, 251-263. doi: 10.1146/annurev.mi.45.100191.001343

Weinert, L. A., Tinsley, M. C., Temperley, M., and Jiggins, F. M. (2007). Are we underestimating the diversity and incidence of insect bacterial symbionts? A case study in ladybird beetles. Biol. Lett. 3, 678-681. doi: 10.1098/rsbl.2007.0373

White, J. F. Jr., and Torres, M. S. (2009). Defensive Mutualism in Microbial Symbiosis. Boca Raton, FL: CRC Press.

Wu, S., Li, R. W., Li, W., Beshah, E., Dawson, H. D., and Urban, J. F. Jr. (2012). Worm burden-dependent disruption of the porcine colon microbiota by Trichuris suis infection. PLOS ONE 7:e35470. doi: 10.1371/journal.pone. 0035470

Conflict of Interest Statement: The authors declare that the research was conducted in the absence of any commercial or financial relationships that could be construed as a potential conflict of interest.

Copyright (c) 2016 Hahn and Dheilly. This is an open-access article distributed under the terms of the Creative Commons Attribution License (CC BY). The use, distribution or reproduction in other forums is permitted, provided the original author(s) or licensor are credited and that the original publication in this journal is cited, in accordance with accepted academic practice. No use, distribution or reproduction is permitted which does not comply with these terms. 